\title{
Constructivism perspective on multimedia games for hearing impaired children
}

Thosporn Sangsawang a ${ }^{*}$,

Suggested Citation:

Trends and Issues Proceedings on Humanities and Social Sciences.

Abstract 
Issues Proceedings on Humanities and Social Sciences.

\section{Introduction}

1.1. Objective of the Study

1.2. Expected Outcomes of the Study

$$
\bullet
$$




\section{Research Methodology}

2.1. Sample

2.2. Instrument for Data Collection

2.3. Data Collection

2.4. Data Analysis

3. Results of the study

First 
Issues Proceedings on Humanities and Social Sciences.

Third

Fourth

Table 1. Step I: Activate prior-knowledge 
Issues Proceedings on Humanities and Social Sciences.

Table 2. Step II: Fine question.

Table 3. Step III: Judge Discovery 


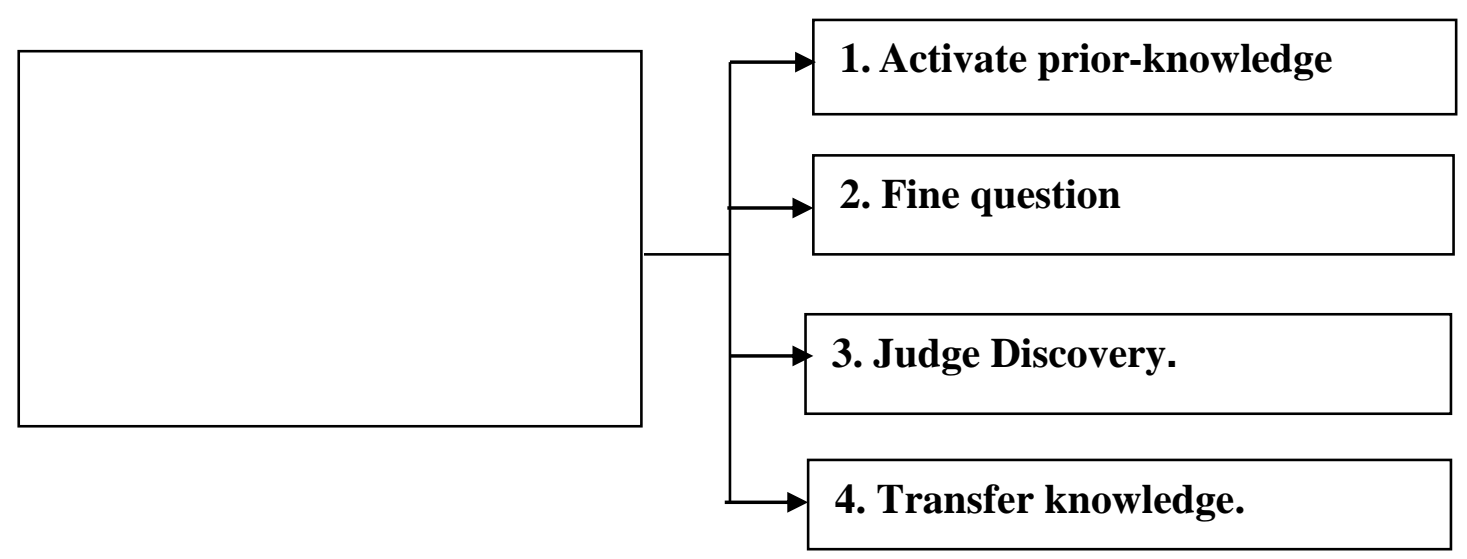

Figure 1. The process of Multimedia Games according to Constructivism Theory For Hearing Impaired Children model 


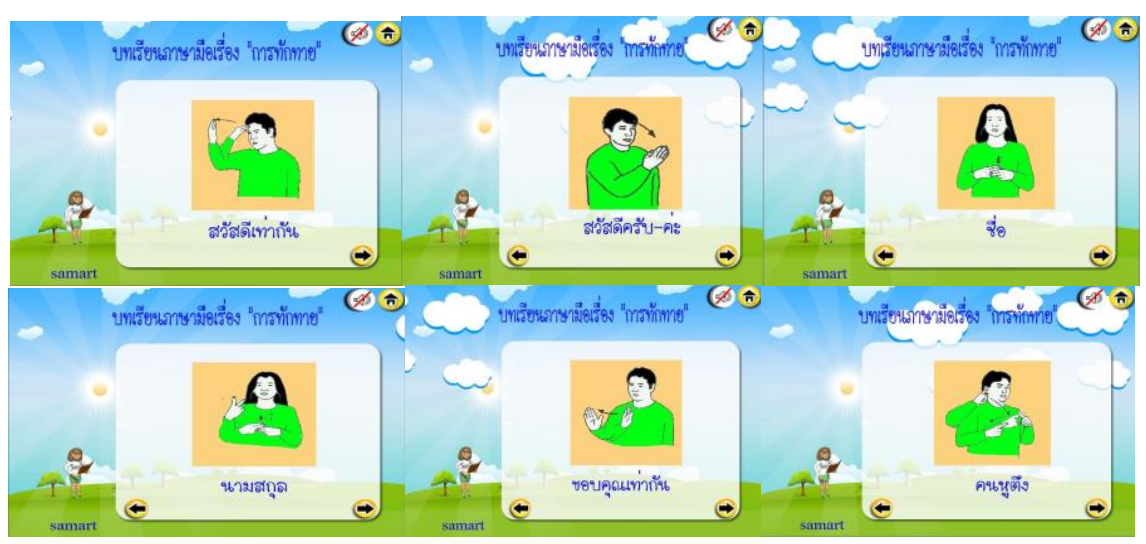

Figure 2. The Multimedia Games according to Constructivism Theory

\section{Discussion}

Hearing Impaired Children, 
Issues Proceedings on Humanities and Social Sciences. 
Issues Proceedings on Humanities and Social Sciences.

Enhancing student learning: Intellectual, social, and emotional integration

To understand is to invent

Education,

Communication \& Information, 2

American

Journal of Distance Education, 16

Education

Media International, 40

Kasetsart University Journal, 1, 